\title{
Knowledge, attitude, perceptions of adult males towards childhood immunizations in southwest Nigeria
}

\author{
Segun Mathew Agboola ${ }^{1}$, Olusegun Adesola Busari ${ }^{2,}$, , Beatrice Titilola Segun-Agboola ${ }^{3}$, \\ Toye Jude Olajide ${ }^{4}$, Olabode Muftau Shabi ${ }^{1}$, Olayide Toyin Elegbede ${ }^{1}$ \\ ${ }^{1}$ Department of Family Medicine, Federal Teaching Hospital, Ido-Ekiti, Nigeria \\ ${ }^{2}$ Department of Internal Medicine, Federal Teaching Hospital, Ido-Ekiti, Nigeria \\ ${ }^{3}$ School of Postbasic Nursing, University of Ilorin Teaching Hospital, Ilorin, Nigeria \\ ${ }^{4}$ Department of Ear, Nose and Throat, Federal Teaching Hospital, Ido-Ekiti, Nigeria
}

Email address:

olubusari@yahoo.com (O. A. Busari)

\section{To cite this article:}

Segun Mathew Agboola, Olusegun Adesola Busari, Beatrice Titilola Segun-Agboola, Toye Jude Olajide, Olabode Muftau Shabi, Olayide Toyin Elegbede. Knowledge, Attitude, Perceptions of Adult Males towards Childhood Immunizations in Southwest Nigeria. American Journal of Health Research. Vol. 3, No. 1, 2015, pp. 8-12. doi: 10.11648/j.ajhr.20150301.12

\begin{abstract}
Background: Immunisation is a cost effective public health intervention in reducing morbidity and mortality from vaccine preventable diseases worldwide. In Nigeria, childhood immunisation against poliomyelitis is still bedeviled by setbacks which are multifactorial. Objectives: The objective of the study was to determine the knowledge, attitude and perceptions of adult males towards childhood immunizations in Nigeria. Methods: The research was a descriptive crosssectional study of adult males in the Ido-Osi local government area of Ekiti state, southwest Nigeria. Multistage sampling method was used to select 320 adult males for the study, and a pre-tested semi-structured questionnaire was used to collect quantitative data. Statistical analysis was done using the Epi Info 4. P value $<0.05$ was considered as statistically significant. Results: Mean age $( \pm \mathrm{SD})$ of the respondents was $48.4 \pm 12.6$ years with range of 20 -95 years. About half $(50.6 \%)$ of the respondents were in the age group 40-59 years. $79.7 \%$ were married while only 2 were single with about two-thirds of the married respondents in monogamous family type. $82.3 \%$ were willing to support childhood immunization. The association between respondents' religion and education, and willingness to support childhood immunization was found to be statistically significant: $\left(\mathrm{x}^{2}=51.53 ; \mathrm{df}=6 ; \mathrm{p}=0.0000\right)$ and $\left(\mathrm{x}^{2}=65.48 ; \mathrm{df}=6 ; \mathrm{p}=0.0000\right)$ respectively. Conclusion: The study showed that the knowledge of adult males about childhood immunization was high. The perception of childhood immunization as a means of protection from certain illnesses was also common and most men were willing to support it. The support for childhood immunization was significantly affected by religion and level of education.
\end{abstract}

Keywords: Childhood Immunisation, Knowledge, Attitudes, Perceptions, Adult Males

\section{Introduction}

Immunisation as a public health intervention is regarded as the most cost effective strategy in reducing morbidity, disability and mortality from vaccine preventable diseases globally. $^{1-3}$ It is for this reason that immunisation was included as an important component of child survival programmes. The child survival programmes were developed by the United Nations Children's Fund to decrease morbidity and mortality of children less than five years of age. ${ }^{1}$ Immunisation has also been described as a weapon of "mass salvation" protecting not only the specific individual but also the entire communities, a term referred to as herd immunity. ${ }^{1}$
The concept of universal immunisation in children that was started in 1985 and was interpreted as the ideal that no child should be denied immunisation against tuberculosis (TB), diphtheria (DT), pertussis (PT), tetanus (TT), poliomyelitis (POLIO) and measles (MS), was never achieved in most countries, including the resource-rich developed nations. ${ }^{4}$ However, the Expanded Programme on Immunisation (EPI) in middle- and low-income countries have prevented more than 2 million child deaths from the above diseases each year since its initiation in $1974 .^{5}$ The establishment of the Global Poliomyelitis Initiative in 1988 has resulted in a $99 \%$ reduction in the worldwide incidence of poliomyelitis. ${ }^{5,6}$ Over the years, a number of other preventable diseases such 
as yellow fever and hepatitis $\mathrm{B}$ infection have been added to the pack. ${ }^{6}$

Nigeria's immunisation programmes have been characterized by intermittent failures and successes since the initial introduction in $1956 .^{7}$ The current coverage rates for the various childhood vaccines in Nigeria are among the lowest in the world. ${ }^{8}$ The country is one of the very few countries in the world that has not interrupted indigenous wild polio virus transmission. ${ }^{7}$ Nigeria has the highest prevalence of circulating wild poliovirus in the world, and accounts for about half of childhood deaths in Africa from measles. ${ }^{9-10}$ The poor immunisation coverage in Nigeria is multifactorial and related to a complex interplay of several socio-economical, religious, cultural and traditional factors characterizing the Nigerian society. Religion and family are two powerful institutions in the Nigerian society and they play critical roles in the health behaviour and practices of the citizens. ${ }^{11-15}$ In a typical black African society, culture and traditions put the male gender over and above the female and men are known to exert immense influence on the reproductive health of their spouses and the general health of the children. ${ }^{16,17}$ The Federal Government of Nigeria in 1988 formulated the National Population Policy which recognizes men as the head of the family who take far reaching decision on family size, subsistence, social relation and health matters. 18,19 The objective of the study was to determine the knowledge, attitude and perceptions of adult males towards childhood immunisation (CI) in Nigeria. The findings of the study might contribute to local policy formulation on immunisation and improve advocacy for immunisation which is an important tool for achieving some of the millennium development goals.

\section{Methods}

The research was a descriptive cross-sectional study of adult males in the Ido-Osi local government area of Ekiti state, southwest Nigeria. Ido-Osi local government area has an estimated population of 107,000 people. The local government area has many health facilities which offer immunisation services. These facilities include a tertiary hospital, a secondary hospital and 15 primary health centres. Multistage sampling technique was used to select 320 adult males for the study. A pre-tested semi-structured questionnaire was used to collect quantitative data on sociodemographic variables, knowledge, attitude, perception and practices of men towards childhood immunisation. Five research assistants were recruited and trained to assist with administration of the questionnaire. Statistical analysis was done using the Epi Info 4. Descriptive analysis was done using frequency and percentages. $\mathrm{P}$ value $<0.05$ was considered as statistically significant.

\section{Results}

Three hundred and twenty (320) male adults residing in Ido-Osi local government area were selected for the study.
Three hundred and ten (310) male adults (96.9\%) responded. The mean age $( \pm \mathrm{SD})$ of the respondents was $48.4 \pm 12.6$ years and the range was $20-95$ years. About half $(50.6 \%)$ of the respondents were in the age group 40-59 years. Two hundred and ten $(67.7 \%)$ respondents were Christians while only 2 $(0.6 \%)$ professed no religion (Table 1$)$. The educational level of the respondents is shown in Table 1. Majority (79\%) were married while only 2 were single. Two hundred and forty five (79\%) of the married participants were in monogamous family relationship while others were polygamous. Other demographic characteristics of the patients are highlighted in Table 1.Most (91.5\%) of the respondents had heard about CI before. Two hundred and sixteen respondents (67.5\%) knew the age of commencement of CI, 69 (21.6\%) did not know, while $35(10.9 \%)$ were not sure.Out of 310 respondents, 254 $(81.9 \%)$ said they supported CI. The association between respondents' religion and willingness to support CI was found to be statistically significant $\left(x^{2}=51.53 ; \mathrm{df}=6\right.$; $\mathrm{p}=0.0000$ ) (Table 2). Also, the association between respondents' level of education and their willingness to support CI showed statistically significant difference $\left(x^{2}=65.48 ; \mathrm{df}=6 ; \mathrm{p}=0.0000\right)$ (Table 3 ).

Table 4 shows the types of vaccine preventable diseases known by the respondents. Polio was the most frequently known of the vaccine preventable diseases while pertussis was the least known (Table 4).Mass media (191/461; 41.4\%) was the most frequent source of information about CI followed by health care workers(HCW) $(160 / 461 ; 34.7 \%)$ and through their wives $(55 / 461 ; 11.9 \%)$.Internet and social media $(4 / 461 ; 0.9 \%)$ was the least frequent source of information.CI was perceived most frequently (78.4\%) as a means of protecting children from certain illnesses (Table 5).Two hundred and fifteen (69.4\%) respondents said men have roles to play in CI (Table 6).

\section{Discussion}

There were 310 adult male respondents from communities within Ido-Osi local government area of Ekiti state, southwest Nigeria. The mean $( \pm \mathrm{SD})$ age was $48.4 \pm 12.6$ years and $64.5 \%$ of the respondents had at least secondary education. With these findings, it could be said, generally, that the respondents are middle-aged literate people. This is consistent with the national literacy rate of $61.3 \%{ }^{20}$ The participants' awareness of CI was very high (91.5\%). This finding corroborates the results of other studies which showed that awareness of CI was 95\% ${ }^{21}$ in Port Harcourt, South Nigeria, $99 \%{ }^{22}$ in Igbo-Ora, South Nigeria, and $94.1 \%$ ${ }^{23}$ in rural communities in India. However, this is contrary to findings in Northern Nigeria where Kabir et al ${ }^{24}$ found that only $75 \%$ of mothers were aware of the existence of routine immunisation services. In our study, the most frequent source of information on CI was traditional mass media and the least was social media. This is consistent with the findings by Jah et al. ${ }^{25}$ This underscores the continual critical role of traditional mass media in health and social services advocacy in resource-poor settings. Although the low contribution of 
social media as a source of information on immunisation in our study might be partly due to low socioeconomic profile of the communities, it however reveals the enormous potential in the emerging social media in advocacy and publicity for the expansion of immunisation coverage in Africa and other developing tropical countries where there are huge digital gaps. A large number of participants in this study knew the age of commencement of CI. This might be due to the fact that most of the participants were literate and could read up the information from the children's immunisation cards.

Also, our study also showed that CI was perceived most frequently $(60 \%)$ as a means of protecting children from certain illnesses while $16.3 \%$ perceived it as part of modernization that is not necessary for child's survival. This is similar to the finding reported by Jah et al ${ }^{25}$ where $61.1 \%$ believed CI offer protection against diseases. Ekanem et al ${ }^{26}$ also showed that $10.6 \%$ of participants in their study were not interested in immunisation because illnesses cannot affect their children. In another study by Ibadin et $a l^{27}, 9.1 \%$ of the participants said they do not believe in immunization.

In this study, polio was the most recognised vaccine preventable childhood diseases under NPI, by $68.8 \%$ of the participants. This was followed by measles recognised by $36.9 \%$, and the least recognised vaccine preventable childhood disease by $29.9 \%$ of the participants was pertussis. This is different from the finding by Nte et al $^{22}$ who reported that measles was the most recognised by $97.4 \%$ of the participants. The high recognition of polio as vaccine preventable disease in the study could be due to intense scale up of activities and new innovations on polio eradication in the past few years which involved introduction of special immunisation days, enormous political will, increased participation of local and international not-for-profit and corporate organizations and religious bodies.

Majority of the participants said men have roles to play in CI. This is consistent with the belief in a traditional African society where the interplay of culture, tradition and religion admits that man is the head of the family and that he takes responsibility for all decisions including health and financial issues. $^{28}$

\section{Conclusions}

The study showed that the knowledge of adult males about CI was high and most frequently obtained through traditional mass media. The perception of CI as a means of protection from certain illnesses was also common and most men were willing to support it. The support for CI was affected by religion and level of education.

Table 1. Socio-demographic characteristics of the respondents.

\begin{tabular}{lll}
\hline Characteristics & Frequency & Percentage \\
\hline Age $(\mathrm{yr})$ & & \\
$20-39$ & 88 & 27.6 \\
$40-59$ & 162 & 50.6 \\
\hline
\end{tabular}

\begin{tabular}{lll}
\hline Characteristics & Frequency & Percentage \\
\hline$\geq 60$ & 60 & 21.9 \\
Religion & & \\
Christianity & 210 & 67.7 \\
Islam & 73 & 23.5 \\
Traditionalism & 25 & 8.1 \\
Not profess any religion & 2 & 0.6 \\
Educational level & & \\
Nil & 43 & 13.9 \\
Primary & 67 & 21.6 \\
Secondary & 90 & 29.0 \\
Tertiary & 110 & 35.5 \\
Marital status & & \\
Single & 2 & 0.6 \\
Married & 245 & 79.0 \\
Widowed & 18 & 5.8 \\
Separated/Divorced & 45 & 14.5 \\
Occupation & & \\
Self-employment & 157 & 50.6 \\
Civil/Public service & 107 & 34.5 \\
Farming & 25 & 8.1 \\
Un-employed & 21 & 6.8 \\
Number of children $<5$ years & & 37.7 \\
Nil & 117 & 55.2 \\
1-2 & 171 & 6.8 \\
3-4 & 21 & 0.3 \\
\hline$\geq 5$ & 1 & \\
\hline & & \\
\hline
\end{tabular}

Table 2. Association between respondents' religion and willingness to support childhood immunization.

\begin{tabular}{lllll}
\hline \multirow{2}{*}{ Religion } & \multicolumn{4}{l}{ Willingness to support childhood immunization } \\
\cline { 2 - 5 } & $\begin{array}{l}\text { No } \\
\text { Freq (\%) }\end{array}$ & $\begin{array}{l}\text { Not sure } \\
\text { Freq (\%) }\end{array}$ & $\begin{array}{l}\text { Yes } \\
\text { Freq (\%) }\end{array}$ & $\begin{array}{l}\text { Total } \\
\text { Freq (\%) }\end{array}$ \\
\hline Christianity & $60(28.6)$ & $21(10.0)$ & $129(61.4)$ & $210(100)$ \\
Islam & $37(50.1)$ & $9(12.3)$ & $27(37.0)$ & $73(100)$ \\
$\begin{array}{l}\text { Traditional } \\
\text { Not profess } \\
\text { any religion }\end{array}$ & $22(88.0)$ & $3(12.0)$ & 0 & $25(100)$ \\
Total & $2(100)$ & 0 & 0 & $2(100)$ \\
\hline
\end{tabular}

$X^{2}=51.53 ; d f=6 ; p=0.000$

Table 3. Association between respondents' educational status and willingness to support childhood immunization.

\begin{tabular}{lllll}
\hline Education & $\begin{array}{l}\text { No } \\
\text { Freq (\%) }\end{array}$ & $\begin{array}{l}\text { Not sure } \\
\text { Freq (\%) }\end{array}$ & $\begin{array}{l}\text { Yes } \\
\text { Freq (\%) }\end{array}$ & $\begin{array}{l}\text { Total } \\
\text { Freq (\%) }\end{array}$ \\
\hline None & $15(34.9)$ & $10(23.3)$ & $18(41.9)$ & $43(100)$ \\
Primary & $3(4.5)$ & $11(16.4)$ & $53(79.1)$ & $67(100)$ \\
Secondary & $3(3.3)$ & $11(12.2)$ & $76(84.4)$ & $90(100)$ \\
Tertiary & $2(1.8)$ & $4(3.6)$ & $104(94.5)$ & $110(100)$ \\
Total & $23(7.0)$ & $36(10.8)$ & $251(82.3)$ & $310(100)$ \\
\hline
\end{tabular}

$\mathrm{x}^{2}=65.48 ; \mathrm{df}=6 ; \mathrm{p}=0.0000$ 
Table 4. Knowledge of respondents on type of vaccine preventable diseasesand places where routine childhood immunization could be administered.

\begin{tabular}{ll}
\hline Vaccine preventable childhood diseases & Frequency(\%) \\
\hline Poliomyelitis & $220(71)$ \\
Measles & $118(35.4)$ \\
Tuberculosis & $118(35.4)$ \\
Yellow fever & $109(35.2)$ \\
Tetanus & $97(31.3)$ \\
Hepatitis & $65(21.0)$ \\
Diptheria & $36(11.6)$ \\
Pertussis & $29(9.4)$ \\
Place(s) of childhood immunization administration & Frequency $(\%)$ \\
Health facilities & $234(36.6)$ \\
Home & $48(15.0)$ \\
School & $4(1.3)$ \\
Market & $2(0.6)$ \\
Not sure & $22(7.1)$ \\
\hline
\end{tabular}

Table 5. Perception of respondents about childhood immunization

\begin{tabular}{ll}
\hline Perception & Frequency(\%) \\
\hline Means of diverting public fund & $32(10.3)$ \\
Part of modernization unnecessary for child's survival & $52(16.8)$ \\
A waste of time and resources & $37(11.9)$ \\
$\begin{array}{l}\text { Fulfilling the wish of government and health care } \\
\text { workers }\end{array}$ & $39(12.6)$ \\
Protecting children from certain diseases & $243(78.4)$ \\
\hline
\end{tabular}

Table 6. Attitude of respondents towards childhood immunization.

\begin{tabular}{ll}
\hline Must children be presented for immunization? & Frequency (\%) \\
\hline Yes & $113(36.5 \%)$ \\
No & $148(47.7 \%)$ \\
Not sure & $49(15.8 \%)$ \\
Does a man have a role to play in childhood & \\
immunization? & \\
Yes & $215(69.4 \%)$ \\
No & $58(18.7 \%)$ \\
Not sure & $37(11.3 \%)$ \\
\hline
\end{tabular}

\section{References}

[1] Park K. Universal immunization programme. In: Park K (Ed) Park's textbook of preventive and social medicine, 18th edition. Jabalpur: India, 2005; 93-100

[2] Omer SB, Salmon DA, Orenstein WA, deHart P, Halsey N. Vaccine refusal, mandatory immunization and the risk of vaccine preventable disease. N Engl J Med 2009; 360: 1981-8

[3] Nyarko P, Pence B, Debpuur C. Immunization status and child survival in rural Ghana. Population Research Division Working Paper No 147, Population Council, New York 2001

[4] Park K. Immunity and immunizing agents. In: Park K (Ed) Park's textbook of preventive and social medicine, 18th edition. Jabalphur, India, 2005; 342-343

[5] WHO, UNICEF. Global immunization vision and strategy, 2006-2015. Geneva, Switzerland and New York, US: WHO and UNICEF; 2005

[6] WHO. Report of the eight meeting of the Technical Consultative Group (TCG) on the Global Eradication of
Poliomyelitis, Geneva, 24-25 April 2003. Geneva, Switzerland: WHO; 2003

[7] AntaiDiddy. Inequitable childhood immunization uptake in Nigeria: a multilevel analysis of individual and contextual determinants. BMC Infectious Diseases 2009, 9: 181. Doi:10.1186/471-2334-9-181

[8] Babalola S, Aina O. Community and systemic factors affecting the uptake of immunization in Nigeria: a qualitative study in five states. National Report, Abuja: PATHS; 2004

[9] World Health Organization. Progress in reducing global measles deaths: 1999-2003. Weekly Epidemiol Rec 2005; 80: $78-81$

[10] Schimmer B, Ihekweazu C. Polio eradication and measles immunization in Nigeria. Lancet Infec Dis 2006; 6: 63-65

[11] Ransome-Kuti O. Common paediatric problems in the tropics. Nigerian Medical Practitioners 1983;3:4-6

[12] Federal Ministry of Health. National Programme on Immunization, Federal Republic of Nigeria: Immunization coverage survey report. 2003; 1-5

[13] Rudolf HT, Bruce RA, David LH. Global eradication of poliomyelitis planning for "final punch" in Africa. MERA 2004 January: vii-viii

[14] Federal Ministry of Health. National Programme on Immunization. Immunization Plus Days Field Guide 2006 (3): $1-20$

[15] World Health Organization. Expanded Programme on Immunization. Immunization activities in Oyo State of Nigeria, 1975-1979. Weekly Epidemiological Record 1980; 55: 265-267

[16] Joseph LM, Harsh B, Sangita Y. Reasons for nonimmunization of children in an urban, low income group in north India. Tropical Doctor 2002; 32: 135-138

[17] Quigley P, Ibrahim GY. Can women's organizations bring health development? Journal of Tropical Paediatrics 1994; 40: 294-298

[18] Akinfeleye R, Feyisetan B, Onidayi AK. Sociocultural factors affecting attitude and behaviour regarding population and family life issues in Nigeria, UNFPA. 2001 (ISBN 978 - 027 092-2).

[19] Salako AA. Traditional religion and parents' attitude to diseases. Nigerian Medical Practioners 2003; 43(3): 54-57

\section{[20] 2013 UN Human Development Report, UN}

[21] Nte AR, Nkanginieme EO. The Expanded Programme on Immunization: the knowledge, attitudes, beliefs and practices of paediatric resident doctors and sixth year medical students at a teaching hospital. Nigerian Postgraduate Medical Journal 1997; 4(4): 118-122

[22] Adeyinka D, Oladimeji O, Adeyinka F, Aimakhu C.Uptake of childhood immunization among mothers of under-five in Southwestern Nigeria. The Internet Journal of Epidemiology 2008; 7 (2):

[23] Hamid S, Andrabi SAH, Fazli A, Jabeen R. Immunization of Children in a Rural Area of North Kashmir, India: A KAP Study. Journal of Health and Allied Sciences 2012; 11(1): 1-4 
[24] Kabir M, Iliyasu Z, Abubakar IS, Gajida AU. Knowledge, perception and beliefs of mothers on routine childhood immunization in a Northern Nigeria village. Annals of Nigerian Medicine 2005; 1(1): 21-26

[25] Jah N, Pokhrel S, Sehgal R. Awareness about a national immunization day programme in the Sunseri district of Nepal. Bulletin of the World Health Organization 1999; 77(7): 602606

[26] Ekanem EE, Asindi AA, Antia-Obong OE. Factors influencing tetanus toxoid immunization among pregnant women in Cross
Rivers state, Nigeria. Nigerian Medical Practitioner 1994; 27(1/2): $3-5$

[27] Ibadin MO, Omogberale AI. Current trend in childhood measles in Benin City, Nigeria. Sahel Medical Journal 1998; 1(1): 6-9

[28] Ngan N. Role of men and grand parents in the families in Vietnam: case study research. Hanoi UNICEF 1995:1-28 